\title{
Health profile of family caregivers of the elderly and its association with variables of care: a rural study
}

\author{
Allan Gustavo Brigolal \\ Bruna Moretti Luchesi' \\ Estefani Serafim Rossetti ${ }^{1}$ \\ Eneida Mioshi² \\ Keika Inouye ${ }^{3}$ \\ Sofia Cristina lost Pavarini ${ }^{3}$
}

\section{Abstract}

Objective: to analyze the profile of a population of caregivers from a city in a rural area of the state of São Paulo, Brazil, and identify their health complaints and the characteristics of care provided. Method: a prospective cross-sectional study was performed based on a domicile survey of 99 caregivers and their elderly care recipients. Information about the profile, context of care and health complaints of the caregivers was collected. The caregivers responded to the Zarit Burden Inventory and the Geriatric Depression Scale-15 and the elderly underwent a cognition and functionality assessment. The chi-squared test with odds ratio (OR) was performed to test associations. Result: the majority of the caregivers were women $(n=76)$, elderly $(n=83)$, with a median age $65.8( \pm 10.4)$ years and $4.9( \pm 4.2)$ years of formal schooling. The most frequent health complaints were pain, systemic hypertension, insomnia, back problems and vision problems. The elderly care recipients were men $(n=75)$, with an average age of $72.0( \pm 8.2)$ years. Analysis of associations revealed that caregivers who received emotional support had a lower chance of being highly overburdened ( $\mathrm{OR}=0.37$; $\mathrm{CI} 95 \% 0.15-0.90)$. Caring for over five years was associated with arthritis $(\mathrm{OR}=2.50$; CI95\% 1.0-6.56). Caring of an elderly person with cognitive impairment was strongly associated with peripheral vascular diseases $(\mathrm{OR}=2.70$; CI95\% 1.11-6.85) and other diseases (OR=6.94; CI95\% 1.43-33.63). Conclusion: A better understanding of the reality of care in rural and remote areas and the identification of factors related to the health care of caregivers provides better care management for the elderly and caregivers, who themselves are aging.

\footnotetext{
Universidade Federal de São Carlos, Programa de pós-graduação em Enfermagem. São Carlos, SP, Brasil.

University of East Anglia, School of Health Sciences. Norwich, Norfolk, Reino Unido.

Universidade Federal de São Carlos, Departamento de Gerontologia. São Carlos, SP, Brasil.
}

Research funding: São Paulo State Research Foundation (FAPESP). Process 2013/26798-9 and Process 2014/23898-5. Type of funding: Master's scholarship

Correspondence

Allan Gustavo Brigola

E-mail: allanbrig@gmail.com
Keywords: Elderly. Caregivers. Rural Population. Family Health Strategy. 


\section{INTRODUCTION}

The chronic stress, depression and anxiety that result from the daily care given to a dependent elderly person can contribute to the detriment of a caregiver's own health and well-being. Damage to health may pose a risk to the quality of care provided to others and to oneself. A meta-analysis has shown that caregivers, especially women and spouses, have higher levels of depression and overburden from the commitment of caring, and lower levels of subjective well-being and perceived health. These caregivers report a greater number of behavioral problems in the recipients of care, and provide more hours of care and carry out more tasks ${ }^{1,2}$.

Literature states that factors that make up the context of care can lead to impairments in the health of caregivers. The time spent providing care, the level of dependence in activities of daily living and the degree of cognitive disorders of the elderly exert significant influences on the perception of health and the overload of the caregiver ${ }^{3-5}$.

In Brazil, data from the Pesquisa Nacional por Amostra de Domicílios (National Household Sample Study) (PNAD) of 2007 showed that approximately $13 \%$ of rural Brazilian adults described a restriction in daily activities due to health reasons and the prevalence of moderate functional disability increases with age ${ }^{6}$, thus highlighting the need for care.

Studies with rural populations have shown that complaints of health impairment such as pain, visual and auditory problems and morbidities such as arthritis, diabetes mellitus and hypertension are prevalent, especially in the elderly ${ }^{7,8}$.

Human longevity has evinced other sociocultural roles. At the family level, as people age, the probability of becoming a caregiver for an elderly relative increases considerably. However, studies with community caregivers are scarce, especially when such individuals are elderly themselves ${ }^{9}$ and live in remote areas $^{9-11}$.

When discussing evidence of the health of caregivers of rural elderly persons, there seems to be a similarity with the findings in literature related to caregivers in general ${ }^{10,11}$. On the other hand, the findings of studies comparing rural and urban contexts do not corroborate. The rural population has been described as suffering due to the distance from health equipment ${ }^{12}$, while the high crime rates, dense, populous and polluted environments that are typical of urban areas increase the risk of health problems ${ }^{13}$. There are often no differences between urban and rural caregivers, making it difficult to characterize the epidemiological profile of these specific populations ${ }^{14,15}$.

The lack of methodological rigor, especially in terms of standardized evaluation tools, coupled with the lack of studies in the rural context and in remote areas, has affected the number of studies with greater power and level of evidence ${ }^{16}$. Therefore, the present study aimed to analyze the profile of the health complaints of family caregivers of elderly people and to identify the characteristics of the context of care provided by caregivers of the rural elderly. The hypothesis was that care characteristics may be associated with a greater number of health complaints in rural caregivers.

\section{METHODS}

The study site comprised the rural area covered by the Family Health Strategy (FHS) of a municipal region in the interior of São Paulo. The municipal region had 18 Family Health Units (FHUs), two of which were located in two rural districts. The municipal region is located in the mid-west of the state of São Paulo, Brazil. It's Human Development Index is 0.805 . According to the 2010 census, the total population was 222,000 , with an estimated 58650 people covered by the FHS. The rural population was 8,870 people and the elderly population exceeded $13 \%$ of the total population of the region ${ }^{17}$.

The study participants were all caregivers and their respective elderly care recipients enrolled in two FHU from two rural districts.

The quantification of the potential participants for composition of the sample was carried out by the healthcare team of the FHU. The criteria established for inclusion in the sample were be a family caregiver 
of an elderly person ( $\geq 60$ years old), live in the rural area, be aged 18 years or older, be more independent than the elderly person, and be primarily responsible for providing assistance in the basic (BADL) and instrumental (IADL) activities of daily living of the elderly. A total of 127 caregivers were registered in the FHU. Of this total, 28 caregivers were excluded because of: change of address $(n=3)$, death $(n=3)$, unable to be located ( $n=15)$, refusal to participate $(n=6)$, and age under 18 years $(n=1)$. The response rate was $77.9 \%(\mathrm{n}=99)$.

Data collection took place during the months of April and December 2014, at the homes of the participants. Caregivers and their respective elderly care recipients were visited only once and invited to participate in the study. The interviews lasted approximately two hours and were always performed with two interviewers, one for the caregiver and one for the elderly person, in separate environments. The interviewers were Gerontology or Nursing graduates and were properly trained to collect information and measure the variables of the study, which occurred through the application of questionnaires and detailed instruments described below.-

\section{Caregiver variables and information}

- Sociodemographic information: gender (male, female), age (continuous and categorized in age groups of ten years), schooling (continuous and categorized in groups of four years of study), marital status (married, unmarried), occupation (categorized according to the sample responses), religion (categorized according to the sample responses), skin color (categorized according to the sample responses), family income (continuous and categorized into number of minimum wages), number of co-residents (continuous), owner of residence (yes, no) and if had private health insurance (yes, no).

- Health conditions: the respondents were asked about health complaints and problems/self-reported morbidities from a list of possible morbidities anemia, anxiety, arthritis, impaired hearing, cancer, constipation, pain, diabetes mellitus, dyslipidemia, systemic arterial hypertension, hypothyroidism, urinary/fecal incontinence, insomnia, obesity, osteoporosis, heart problems, spinal problems, gastrointestinal problems, vision problems, lung problems, falls, dizziness/vertigo, varicose veins (yes, no), use of medications (yes/no), calculation of Body Mass Index (BMI), from the assessment of the weight $(\mathrm{kg})$ and height $(\mathrm{m})$ of the caregivers, (with BMI between 22 and $27 \mathrm{~kg} / \mathrm{m}^{2}$ for elderly caregivers and between 18.5 and $24.99 \mathrm{~kg} / \mathrm{m}^{2}$ for adult caregivers considered normal, and lower or higher levels considered underweight and overweight respectively), healthy diet (yes, no), self-rated health (very good/good, fair, poor/very poor), self-rated care of own health (very good/good, fair, poor/ very poor) and overall satisfaction with life (very, somewhat, not very).

- Perceived overload: evaluation conducted through the Zarit Burden Inventory (ZBI), validated for the Brazilian context $\mathrm{t}^{18}$. This questionnaire comprises 22 Likert response questions. The score on each response varied from 0 -Never to 4-Always, and the final score of the instrument was given by the sum of the answers, totaling a value between 0 and 88. The higher the score the greater the perceived overburden of the caregiver. The classification used was low overburden $<21$, moderate overburden 21-40 and moderate to severe overburden $\geq 41^{18}$.

- Depressive symptoms: measured by the Geriatric Depression Scale (GDS) 15 question version, developed for the screening of depressive symptoms. The scale is validated for the Brazilian context and the cut-off point used was $>5$ for indications of symptoms $^{19}$.

Information on care context

- Care characteristics: kinship/proximity to the cared-for elderly person (spouse, father/mother, others), time of care (continuous and categorized in five year groups), hours per day (continuous) and days of the week dedicated to care (continuous), participation in courses/training for caregivers (yes, no), if caregiver receives help and type of help received (affective/emotional, material/financial, others). 
Variables of elderly person receiving care

- Sociodemographic information: age (continuous) and gender (male, female).

- Cognitive screening: performed through the Mini Mental State Exam (MMSE, score 0 to 30 points), validated for use in Brazil with a suggested classification according to schooling $(<17$ points for illiterate, $<22$ points for 1 to 4 years of schooling, $<24$ points for 5 to 8 years of schooling and $<26$ points for 9 years or more of schooling $)^{20}$.

- Activities of daily living: a combination of instruments validated for use in Brazil. In order to evaluate BADL, the Katz Index was used to evaluate dependence in six activities - bathing, dressing, toileting, transfer, sphincter control, feeding - with a score of 0-6 being considered as dependent. For IADL, the Lawton and Brody Scale was applied, which involves questions related to telephone use, travel, shopping, preparing meals, housework, drug use and money management, and ranges from 7 to 21 points. The classification used was 8-20 for partial dependence and 7 for total dependence ${ }^{22}$.

Initially, descriptive statistical analysis was performed. The Kolmogorov-Smirnov test was used and it was verified that the data did not show adherence to normality.

The multi-analyses sought to verify associations between the variables of the health profile of the caregivers, treated as dependent variables, and information regarding the care context, treated as independent variables. The demographic and social characteristics of the caregivers, such as age, gender and schooling were also tested against their health profile. The chi-square test with odds ratio (OR) and confidence intervals at 95\% (CI95\%) were used to analyze the associations between the dependent and independent categories. Additionally, correlation analyzes were performed using the Spearman Correlation Coefficient $(r)$ among the continuously constructed variables, adopting alpha correction as a function of the number of correlations. The associations and correlations considered statistically significant $(\not$-value $\leq 0.05)$ are presented in the tables.
All the participants provided written consent for their participation in the study (Declaration of Helsinki and Resolution 466/12). The study was approved by the ethics committee in regional research (n. 517.182).

\section{RESULTS}

The caregivers were mostly women ( $\mathrm{n}=76$ ), elderly $(\mathrm{n}=83)$, with a mean age of 65.8 years and between one and four years of formal schooling $(70.7 \%)$, as shown in Table 1.

Other sociodemographic information showed that the caregivers were mostly married $(\mathrm{n}=89$, $89.9 \%$ ), did not perform paid work ( $\mathrm{n}=76,76.8 \%$ ), were retired $(n=50,50.5 \%)$, described themselves as white $(\mathrm{n}=70,70.3 \%)$ and Catholic $(\mathrm{n}=66,66.7 \%)$. The average monthly family income was $\mathrm{R} \$ 2671.90$ $( \pm 2187.50), 71.4 \%(\mathrm{n}=70)$ received two or more minimum wages ( $\mathrm{R} \$ 724.00$ for the year 2014), did not have private health insurance $(\mathrm{n}=80,80.8 \%)$, lived with other people $(2.9 \pm 1.4$ people in the same house), and owned their own homes ( $\mathrm{n}=80,80.8 \%)$.

The health information reported by caregivers showed a low prevalence of health impairments. The screening instruments showed a slight perceived overburden in the ZBI and $16.2 \%$ had depressive symptoms according to the GDS (Table 2).

The most frequent health complaints among caregivers were pain, systemic arterial hypertension, spinal problems, insomnia, and vision problems. Other complaints of morbidities such as anemia, impaired hearing, cancer, constipation, hypothyroidism, urinary/fecal incontinence, obesity, osteoporosis and pulmonary problems were reported at a frequency of less than $10 \%$ and are not described in Table 2.

Almost $80 \%$ of caregivers used at least one medication continuously and polypharmacy (use of $\geq 5$ medications continuously) was present in $54.5 \%$ $(\mathrm{n}=54)$ of caregivers. Most reported healthy eating habits, which included the daily intake of fruits and vegetables $(n=89,89.9 \%)$. 
Table 1. Descriptive analysis and analysis of distribution of caregivers in the rural community according to age, gender and schooling (n=99). São Carlos, São Paulo, 2014.

\begin{tabular}{ll}
\hline Variables/Categories & $\mathrm{n}(\%)$ or mean $( \pm$ sd $)$ \\
\hline Age (years) & $65.8( \pm 10.4)$ \\
Age range & $16(16.2)$ \\
$<60$ & $53(53.5)$ \\
$60-69$ & $20(20.2)$ \\
$70-79$ & $10(10.1)$ \\
$\geq 80$ & \\
Gender & $76(76.8)$ \\
Female & $23(23.2)$ \\
Male & $4.9( \pm 4.2)$ \\
Schooling (years) & \\
Schooling level & $6(6.1)$ \\
$<1$ & $70(70.7)$ \\
1 to 4 & $5(5.1)$ \\
5 to 8 & $18(18.2)$ \\
$\geq 9$ &
\end{tabular}

$\mathrm{sd}=$ standard deviation

Table 2. Descriptive analysis and analysis of distribution of caregivers in the rural community according to health variables (n=99). São Carlos, São Paulo, 2014.

\begin{tabular}{|c|c|}
\hline Variables/Categories & $\mathrm{n}(\%)$ or mean $( \pm \mathrm{sd})$ \\
\hline Zarit Burden Inventory (points) & $18.4( \pm 14.9)$ \\
\hline \multicolumn{2}{|l|}{ Level of overburden } \\
\hline None/mild & $67(67.7)$ \\
\hline Moderate & $24(24.2)$ \\
\hline Moderate/Severe & $8(8.1)$ \\
\hline Geriatric Depression Scale-15 (points) & $3.3( \pm 2.8)$ \\
\hline \multicolumn{2}{|l|}{ Analysis of depressive symptoms } \\
\hline No indication & $83(83.8)$ \\
\hline Indicated & $16(16.2)$ \\
\hline Related Morbidities (number) & $4.7( \pm 2.8)$ \\
\hline \multicolumn{2}{|l|}{ Types } \\
\hline Anxiety & $26(26.3)$ \\
\hline Arthritis & $29(29.3)$ \\
\hline Pain & $57(58.2)$ \\
\hline Diabetes Mellitus & $23(23.2)$ \\
\hline Dyslipidemias & $10(10.2)$ \\
\hline Systemic Arterial Hypertension & $49(49.4)$ \\
\hline Insomnia & $41(41.4)$ \\
\hline Cardiac problems & $12(12.1)$ \\
\hline Back problems & $43(43.4)$ \\
\hline Gastrointestinal problems & $17(17.2)$ \\
\hline
\end{tabular}


Continued from Table 2

\begin{tabular}{|c|c|}
\hline Variables/Categories & $\mathrm{n}(\%)$ or mean $(\underline{\mathrm{sd}})$ \\
\hline Vision problems & $39(39.4)$ \\
\hline Falls* & $34(34.3)$ \\
\hline Dizziness/Vertigo & $25(25.3)$ \\
\hline Varicose Veins & $28(28.3)$ \\
\hline Medications being used (number) & $2.4( \pm 2.3)$ \\
\hline \multicolumn{2}{|l|}{ Frequency } \\
\hline Yes & $77(77.8)$ \\
\hline No & $22(22.2)$ \\
\hline \multicolumn{2}{|l|}{ Subjective evaluation of health } \\
\hline Very good/Good & $68(68.7)$ \\
\hline Fair & $28(28.3)$ \\
\hline Very poor/Poor & $3(3.0)$ \\
\hline \multicolumn{2}{|l|}{ Evaluation of care of own health } \\
\hline Very good/Good & $56(56.6)$ \\
\hline Fair & $34(34.3)$ \\
\hline Very poor/Poor & $9(9.1)$ \\
\hline \multicolumn{2}{|l|}{ Overall satisfaction with life } \\
\hline Very satisfied & $77(77.8)$ \\
\hline Somewhat satisfied & $21(21.2)$ \\
\hline Not very satisfied & $1(1.0)$ \\
\hline \multicolumn{2}{|l|}{ Body Mass Index } \\
\hline Underweight & $13(13.1)$ \\
\hline Normal weight & $35(35.4)$ \\
\hline Overweight & $51(51.5)$ \\
\hline
\end{tabular}

*in last 12 months. $\mathrm{Sd}=$ standard deviation.

Table 3 displays information regarding the context of care. The caregivers had provided care to the elderly for more than five years $(54.8 \%)$, every day of the week, for five hours a day or more $(n=64$, $67.6 \%$ ). The profile of the elderly care recipient was male, with no evidence of cognitive impairment $(53.5 \%)$ who were mainly dependent in IADL (91.9\% were partially dependent and $8.1 \%$ were totally dependent).

An important result was the reporting by the caregiver of help from health institutions and services in $53.5 \%$ ( $n=53$ ) of cases, mainly through the supply of free medicines. Support was reported from other areas, such as religious groups $(\mathrm{n}=11,11.1 \%)$ and social services $(\mathrm{n}=8,8.2 \%)$.
Table 4 shows the strongest associations between the health profile of the caregivers and the context of care. Receiving affective/emotional help was inversely related to the highest level of caregiver overburden. Caregivers of elderly women were less likely to report vascular diseases and a poor self-rating of health. Caregivers who provided care for more than five years and cared for elderly persons with evidence of cognitive changes were more likely to complain of vascular diseases and other morbidities. In Table 5, correlation analysis showed that caregiver's schooling was directly associated with BMI. After alpha correction, the analyzes showed weak associations between the number of medications used by the caregiver and the amount of days per week spent providing care (direct relationship) and between the age of the caregiver and ZBI score (inverse relationship). 
Table 3. Descriptive analysis and analysis of distribution of elderly persons receiving care and context of care and of the rural community (n=99). São Carlos, São Paulo, 2014.

\begin{tabular}{|c|c|}
\hline Variables/Categories & $\mathrm{n}(\%)$ or mean $( \pm \mathrm{sd})$ \\
\hline Age (years) & $72.0( \pm 8.2)$ \\
\hline \multicolumn{2}{|l|}{ Gender } \\
\hline Male & $74(74.7)$ \\
\hline Female & $25(25.3)$ \\
\hline Mini Mental State Exam (points) & $20.3( \pm 7.1)$ \\
\hline \multicolumn{2}{|l|}{ Analysis of cognitive disorder } \\
\hline Indication of disorder & $46(46.5)$ \\
\hline No indication of disorder & $53(53.5)$ \\
\hline Basic activities of daily living (points) & $5.3( \pm 1.4)$ \\
\hline \multicolumn{2}{|l|}{ Dependency in: } \\
\hline Bathing & $13(13.1)$ \\
\hline Dressing & $14(14.1)$ \\
\hline Going to the bathroom & $9(9.1)$ \\
\hline Transferring & $8(8.1)$ \\
\hline Sphincter control & $17(17.2)$ \\
\hline Feeding & $6(6.1)$ \\
\hline Instrumental activities of daily living (points) & $14.6( \pm 3.8)$ \\
\hline \multicolumn{2}{|l|}{ Dependent in: } \\
\hline Using the telephone & $43(43.4)$ \\
\hline Travelling & $52(52.5)$ \\
\hline Shopping & $69(69.7)$ \\
\hline Preparing meals & $72(72.7)$ \\
\hline Domestic chores & $68(68.7)$ \\
\hline Taking medication & $30(30.3)$ \\
\hline Managing money & $57(57.6)$ \\
\hline \multicolumn{2}{|l|}{ Family relationship } \\
\hline Spouse & $81(81.8)$ \\
\hline Parents & $10(10.1)$ \\
\hline Others & $8(8.1)$ \\
\hline Length of time of providing care (months)* & $126.4( \pm 157.7)$ \\
\hline \multicolumn{2}{|l|}{ Length of time providing care (years/groups) } \\
\hline$<5$ & $42(45.2)$ \\
\hline 5 to 10 & $27(29.0)$ \\
\hline$<10$ & $24(25.8)$ \\
\hline Care/day (hours) & $8.2( \pm 5.1)$ \\
\hline Care/week (days) & $6.8( \pm 0.6)$ \\
\hline Care related spending/month (reais) & $219.3( \pm 673.9)$ \\
\hline \multicolumn{2}{|l|}{ Training/course in caring } \\
\hline Yes & $5(5.1)$ \\
\hline No & $94(94.9)$ \\
\hline \multicolumn{2}{|l|}{ Receives affective/emotional assistance** } \\
\hline Yes & $49(50.0)$ \\
\hline No & $49(50.0)$ \\
\hline \multicolumn{2}{|l|}{ Receives material/financial assistance } \\
\hline Yes & $18(18.2)$ \\
\hline No & $81(81.8)$ \\
\hline
\end{tabular}

sd $=$ standard deviation; $*$ did not respond $=6 ; * *$ did not respond $=1$ 
Table 4. Multi-analysis of association between information of care and health variables of caregiver $(\mathrm{n}=99)$. São Carlos, São Paulo, 2014.

\begin{tabular}{|c|c|c|c|c|}
\hline \multirow[b]{2}{*}{ Health variables } & \multicolumn{4}{|c|}{ Information of context of care } \\
\hline & $\begin{array}{l}\text { Receives emotional } \\
\text { support }\end{array}$ & $\begin{array}{l}\text { Cares for female } \\
\text { elderly person }\end{array}$ & $\begin{array}{l}\text { Time of care } \geq 5 \\
\text { years }\end{array}$ & $\begin{array}{l}\text { Care for elderly } \\
\text { person with } \\
\text { cognitive disorder }\end{array}$ \\
\hline Severe overburden & $\begin{array}{l}\mathrm{OR}=0.37 ; \mathrm{CI} 95 \% \\
0.15-0.90 *\end{array}$ & - & - & - \\
\hline $\begin{array}{l}\text { Evaluation of health Fair/ } \\
\text { Poor/Very Poor }\end{array}$ & - & $\begin{array}{l}\mathrm{OR}=0.33 \\
\mathrm{CI} 95 \% 0.10-1.0^{*}\end{array}$ & - & - \\
\hline Report of arthritis & - & - & $\begin{array}{l}\mathrm{OR}=2.50 ; \mathrm{CI} 95 \% \\
1.0-6.56 *\end{array}$ & - \\
\hline $\begin{array}{l}\text { Report of vascular illnesses } \\
\text { (varicose veins) }\end{array}$ & - & $\begin{array}{l}\mathrm{OR}=0.16 ; \mathrm{CI} 95 \% \\
0.03-0.73 *\end{array}$ & - & $\begin{array}{l}\mathrm{OR}=2.70 \\
\mathrm{CI} 95 \% 1.11-6.85^{*}\end{array}$ \\
\hline $\begin{array}{l}\text { Report of non-specified } \\
\text { morbidities }\end{array}$ & - & - & - & $\begin{array}{l}\mathrm{OR}=6.94 ; \\
\text { CI95\% } 1.43-33.63^{*}\end{array}$ \\
\hline
\end{tabular}

${ }^{*}$ Chi-square test; $\mathrm{OR}=$ odds ratio; $\mathrm{CI} 95 \%=95 \%$ confidence interval.

Table 5. Multi-analyses of correlation between information of caregiver and continuous variable of health of caregiver (n=99). São Carlos, São Paulo, 2014.

\begin{tabular}{llll}
\hline \multirow{2}{*}{ Health variables } & \multicolumn{2}{l}{ Information of context of care } & \\
& Age of caregiver (years) & Care in days/week & Schooling of caregiver (years) \\
\hline Overburden of caregiver (ZBI) & $r_{s}=-0.20 ; p=0.04^{2}$ & - & - \\
\hline Number of medications & - & $r_{s}=0.21 ; p=0.03^{2}$ & - \\
\hline Body Mass Index & - & - & $r_{s}=0.22 ; p=0.02$ \\
\hline
\end{tabular}

$r_{s}=$ Spearman Correlation Coefficient; ${ }^{2}$ Alpha correction (Bonferroni Correction: alpha $<0.025$ ); ZBI=Zarit Burden Inventory.

\section{DISCUSSION}

The profile of the elderly caregiver identified resembles the results of other studies. Caregivers have been found to be family members, female, usually the daughter or wife of the elderly person receiving care, and aged between 50 and 60 years, according to Brazilian ${ }^{23,24}$ and international studies ${ }^{14,25,26}$. The majority of caregivers have an unfinished elementary education ${ }^{4,23-25}$, are unemployed or dedicate themselves solely to domestic activities ${ }^{24}$.

Regarding the profile of elderly people living in rural areas, specific studies have found that the majority are female and married, the prevalent age group is 60 to 69 years $^{6}$, and only $10 \%$ of elderly persons are aged 80 years or more ${ }^{6}$. The percentage of adult women living in rural areas who are widowed is higher than the percentage of adult male widowers. The same is observed in older elderly persons in comparison with their younger counterparts. Most declared themselves white and of Catholic religion ${ }^{27}$.

The level of schooling is low and the illiteracy rate is high, with men more educated than women. The majority had a low income, spent a large part of their money on food and medicines and lived with relatives in the same house ${ }^{27}$.

A large part of the sample did not have a private health plan. Data from the PNAD show that in 2003 , the main financer of the system of care of people aged 60 years or more in rural areas was the Sistema Único de Saúde (the Unified Health System) (SUS) (70.6\%) followed by own financing (14.0\%) and private health plans $(8.3 \%)^{6}$. The data found in 
this study for the profile of the elderly corroborate the findings in literature.

With regard to health conditions, the literature is divergent. Caregivers described fatigue, stress and overburden when evaluating their health status, 4,24,25. In a sample of caregivers in Chile, moderate levels of overload were found related not only to the act of caring, but also to the shortages in the support network and physical incapacities ${ }^{28}$. Although distanced from formal support services, the elderly and caregivers residing in rural areas may perceive their health better than the elderly and caregivers of urban areas ${ }^{29}$. However, the present study could not verify this relationship due to the absence of a group of caregivers from urban communities.

This can be confirmed from PNAD data. From the evaluation of the health needs profile of the elderly population living in rural areas in 2003 , a prevalence of $16.6 \%$ of people self-rated their health status as poor or very poor. The negative self-perception of health increased significantly with age and was lower in relation to the urban elderly ${ }^{6}$. Similarly, in another study comparing the rural elderly with the elderly in urban areas, the authors verified that the latter had fewer morbidities and also had a higher quality of life score in the physical and social domains, and in the facets autonomy, past, present and future activities and intimacy ${ }^{29}$.

In Rio Grande do Sul, Brazil, it was demonstrated that the majority of the rural elderly self-assessed their health as regular, and an association was found with age. The elderly between the ages of 80 and 84 described their health as worse, while 85-89 year olds reported their health as excellent ${ }^{30}$. Area of residence may be related to improved health perception ${ }^{12,13}$. In the present study, many of the caregivers reported being satisfied with their health, life and the care they took of themselves.

In terms of morbidities, in another study in a rural context in southern Brazil, the results showed that joint diseases (rheumatism, arthrosis, arthritis), spinal problems, insomnia, arterial hypertension, cataracts, nerves and heart are the most frequent ${ }^{27}$. In rural elderly people in Minas Gerais, Brazil, hypertension, spinal and vision problems were the most prevalent conditions $^{29}$. Health impairment and complaints can be influenced by factors related to the aging of the caregivers themselves. It can be observed that the elderly who provide care and those who do not have a similar health profile, both in the rural context.

A survey in the rural area of Minas Gerais, Brazil, with 2898 elderly people, and a review study that described the factors associated with health may explain this finding. The results showed that the factors associated with symptoms of depression, for example, were female and age. Multivariate analyzes revealed that the female gender, being 80 years of age or older, not having a partner, having no schooling, having a greater number of functional limitations and a greater number of morbidities were factors related to a depressed $\operatorname{mood}^{31,32}$.

In terms of characteristics of care, Brazilian literature reveals information similar to the findings of the present study. Caregivers provided care for more than 10 hours a day ${ }^{23,33,34}$. Just over half of all caregivers provided care full time, with about $40 \%$ not receiving support from other people and having no previous training in the activity ${ }^{4}$. Around $70 \%$ were married ${ }^{24}$.

A literature review has shown that the caregiver's work is aimed at the activities in which the elderly person describes limitations. Helping with eating, skin integrity, hygiene, bowel eliminations, therapy, locomotion and movement, preparation of meals, care of clothes, cleaning of the house and carrying out of tasks outside the home were the most frequent ${ }^{24}$. In the present study, no relationship was found between the activities carried out by the caregiver and their profile of health complaints. Activities carried out throughout life, especially among caregiver spouses, may not be sufficient to cause health impairment. However, a new development in the life of the couple, such as a change in cognition, is a factor that can cause burdens on the health of those who provide care.

The greater number of people who live with elderly persons in the rural area may result in greater affective support, as evidenced by a study in the state of São Paulo, Brazil ${ }^{35}$. This study also pointed out that reduced social support was more frequent for women, who were illiterate, widowed or single, and in the elderly with an income of between one and two minimum wages ${ }^{35}$. Personal relationships in a home environment in the context of care should be explored in greater depth in future research, as 
caregiver overburden may be influenced by the greater or lesser help from third parties for the care recipient.

Cognitive disorders among the elderly persons were associated with reports of varicose veins in caregivers. No studies were found to explain this relationship. One study showed that the occurrence of cognitive impairment prevails among elderly persons aged 80 and older, without an occupation or schooling, who were widowed, had vision problems, cardiac problems and hypertension, and six or more functional disabilities ${ }^{31}$. It is important to highlight that elderly caregivers are also exposed to these risk factors for the cognitive performance of the elderly. The salient factors can be determinant for the cognition and the functionality of the caregiver, and consequently the quality of the care provided.

In the majority of the elderly, independence in the basic activities of daily living was maintained; however, the absence of schooling, the advancement of age and the greater number of morbidities may be associated with functional incapacity for the performance of instrumental activities of daily living. One study found that the basic activities with the highest frequency of disabilities are bathing and dressing, and telephone use and household chores among more complex activities ${ }^{27}$. The authors also showed that approximately $35 \%$ of the elderly were independent and $55 \%$ were partially dependent in ADL. In analysis by gender, women presented higher percentages of mild, moderate and severe dependence $(63.2 \%, 10.5 \%$ and $5.3 \%$ respectively) than men $(40.0 \%, 6.7 \%$ and $0 \%$, respectively), who were more independent ${ }^{27}$.

This study provided information on the profile of caregivers and elderly care recipients, as well as on the health complaints of caregivers and the care they took of themselves, and sought to identify care context information related to caregiver health. The absence of a comparative group of caregivers from urban areas is a limitation that can be overcome in future studies. In addition, follow-up analysis of the participants could allow predictive and cause-andeffect analyzes.

\section{CONCLUSIONS}

The caregivers of the elderly in the rural areas of this study were predominantly women, elderly, married, with one to four years of schooling, declared themselves as white, retired and Catholic.

The most frequent health complaints were pain, systemic arterial hypertension, insomnia, spinal problems and vision problems. Overburden was marginally associated with the advanced age of the caregiver, and strongly associated with a lack of affective or emotional help. Elderly caregivers of female elderly persons exhibited positive self-rated health and reported a lower occurrence of varicose veins. Arthritis was more prevalent in those who had provided care for more than five years, and this complaint and unspecified morbidities were strongly associated with caring for an elderly person with cognitive impairment.

The present study presents information from caregivers who provide care to the elderly in the community, without specifying the pathology that affects the dependent elderly person. Understanding the reality of care in rural areas and identifying care factors related to the health of caregivers can contribute to better care management for elderly persons and their caregivers. The combination of subjective and objective health assessment instruments may be significant in the context of primary health care in Brazil.

Other studies may be carried out to provide a deeper understanding of co-variables related to the aging of the caregiver and the context of care. In addition to the biopsychosocial context, the quality of the aging of the caregiver can be dictated by many characteristics of the care itself, such as receiving support from third parties, long periods of care and the profile of the elderly person being cared for. These characteristics may explain the influence on the health and well-being of the caregiver and their quality of life. Finally, it should be considered that most caregivers are also elderly and there is a need for attention to this scenario which is growing in scale and significance.

\section{ACKNOWLEDGEMENTS}

The authors would like to thank all the caregivers and elderly persons who participated in the present study. 


\section{REFERENCES}

1. Pinquart M, Sorensen S. Associations of stressors and uplifts of caregiving with caregiver burden and depressive mood: a meta-analysis. J Gerontol Ser B Psychol Sci Soc Sci. 2003;58(2):112-28.

2. Pinquart M, Sorensen S. Spouses, adult children, and children-in-law as caregivers of older adults: a metaanalytic comparison. Psychol Aging. 2011;26(1):1-14.

3. Bourgeois J, Ochs J, Tyrrell J. Vigilance: a core feature of caregiver burden in dementia [abstract]. Alzheimer's Dement. 2009;5(4):91.

4. Gratão ACM, Talmelli LFS, Figueiredo LC, Rosset I, Freitas CP, Rodrigues RAP. Dependência funcional de idosos e a sobrecarga do cuidador. Rev Esc Enferm USP [Internet]. 2013 [acesso em 28 nov. 2016];47(1):137-44. Disponível em: http://www.scielo. br/pdf/reeusp/v47n1/a17v47n1.pdf.

5. Lillo P, Mioshi E, Hodges JR. Caregiver burden in amyotrophic lateral sclerosis is more dependent on patients' behavioral changes than physical disability: a comparative study. BMC Neurol. 2012;12:1-11.

6. Travassos C, Viacava F. Acesso e uso de serviços de saúde em idosos residentes em áreas rurais, Brasil, 1998 e 2003. Cad Saúde Pública. 2007;23(10):2490-502.

7. Curcio CL, Gomez F, Reyes-Ortiz CA. Related to fear of falling. J Aging Health. 2009;21(3):460-79.

8. Curcio CL, Henao GM, Gomez F. Frailty among rural elderly adults. BMC Geriatr. 2014;14(1):1-8.

9. Luchesi BM, Alexandre TS, Oliveira NA, Brigola AG, Kusumota L, Pavarini SCI, et al. Factors associated with attitudes toward the elderly in a sample of elderly caregivers. Int Psychogeriatr. 2016;28(12):1-11.

10. Morgan DG, Kosteniuk JG, Stewart NJ, O’Connell ME, Kirk A, Crossley M, et al. Availability and primary health care orientation of dementia-related services in rural Saskatchewan, Canada. Home Health Care Serv Q. 2015;34(3-4):137-58.

11. Stewart NJ, Morgan DG, Karunanayake CP, Wickenhauser JP, Cammer A, Minish D, et al. Rural caregivers for a family member with dementia: models of Burden and Distress differ for women and men. J Appl Gerontol. 2014; 35(2):150-78.

12. Li LW, Liu J, Xu H, Zhang Z. Understanding rural-urban differences in depressive Ssymptoms among older adults in China. J Aging Health. 2016; 22;28(2):341-62.

13. McKenzie K, Murray A, Booth T. Do urban environments increase the risk of anxiety, depression and psychosis? an epidemiological study. J Affect Disord. 2013;150(3):1019-24.
14. Brazil K, Kaasalainen S, Williams A, Rodriguez C. Comparing the experiences of rural and urban family caregivers of the terminally ill. Rural Remote Health. 2013;13(1):1-12.

15. Brazil K, Kaasalainen S, Williams A, Dumont S. A comparison of support needs between rural and urban family caregivers providing palliative care. Am J Hosp Palliat Care. 2014;31(1):13-9.

16. Gessert C, Waring S, Bailey-Davis L, Conway P, Roberts M, VanWormer J. Rural definition of health: a systematic literature review. BMC Public Health 2015;15:378.

17. Instituto Brasileiro de Geografia e Estatística, Diretoria de Pesquisas, Coordenação de Trabalho e Rendimento. Pesquisa Nacional por Amostra de Domicílios 2013 [Internet]. Brasília, DF; 2013 [acesso em 15 abr. 2017]. Disponível em: http:// www.ibge.gov.br/home/estatistica/populacao/ trabalhoerendimento/pnad2013/default_sintese.shtm

18. Scazufca M. Brazilian version of the Burden Interview scale for the assessment of burden of care in carers of people with mental illnesses. Rev Bras Psiquiatr. 2002;24(1):12-7.

19. Almeida OP, Almeida SA. Confiabilidade da versão brasileira da Escala de Depressão em Geriatria (GDS) versão reduzida. Arq Neuropsiquiatr. 1999;57(2B):421-6.

20. Brucki SMD, Nitrini R, Caramelli P, Bertolucci PHF, Okamoto IH. Suggestions for utilization of the mini-mental state examination in Brazil. Arq Neuropsiquiatr. 2003;61(3B):777-81.

21. Katz S, Ford AB, Moskowitz RW, Jackson BA, Jaffe MW. Studies of illness in the aged. The index of ADL: a standardized measure of biological and psychosocial function. JAMA. 1963;185:914-9.

22. Lawton MP, Brody EM. Assessment of older people: self-maintaining and instrumental activities of daily living. Gerontologist. 1969;9(3):179-86.

23. Garces SBB, Krug MR, Hansen D, Brunelli AV, Da Costa FTL, Rosa CB, et al. Avaliação da resiliência do cuidador de idosos com Alzheimer. Rev Bras Geriatr Gerontol. 2012;15(2):335-52.

24. Vieira CPB, Fialho AVM, De Freitas CHA, Jorge MSB. Practices of elderly's informal caregiver at home. Rev Bras Enferm. 2011;64(3):570-9.

25. Fernández-Lansac V, Crespo López M, Cáceres R, Rodríguez-Poyo M. Resiliencia en cuidadores de personas con demencia: Estudio preliminar. Rev Esp Geriatr Gerontol. 2012;47(3):102-9. 
26. Toribio-Díaz E, Moltó-Jordà J, Martinez VM, Perez-Cerda I, Bermejo-Velasco P, Zea-Sevilla MA. Formal caregivers in assisted residences of the province of Alicante, Spain: analysis of their needs and expectations of formation in dementias [abstract]. Alzheimers Dement. 2011;7(4):434.

27. Rigo II, Paskulin LMG, Morais EP de. Capacidade funcional de idosos de uma comunidade rural do Rio Grande do Sul. Rev Gaúcha Enferm 2010;31(2):254-61.

28. Aravena VJ, Alvarado OS. Evaluación de la sobrecarga de cuidadoras/es informales. Cienc Enferm. 2010;15(2):111-20.

29. Santos EA, Tavares DMS, Rodrigues LR, Dias FA, Ferreira PCS. Morbidades e qualidade de vida de idosos com diabetes mellitus residentes nas zonas rural e urbana. Rev Esc Enferm USP. 2013;47(2):393-400.

30. Morais EP, Rodrigues RAP, Gerhardt TE. Os idosos mais velhos no meio rural: realidade de vida e Saúde de uma população do interior gaúcho. Texto Context Enferm. 2008;17(2):374-83.
31. Ferreira PCS, Tavares DMS, Rodrigues RAP. Características sociodemográficas, capacidade funcional e morbidades entre idosos com e sem declínio cognitivo. Acta Paul Enferm. 2011;24(1):29-35.

32. Luchesi BM, Degani GC, Brígola G, Pavarini SCI, Marques S. Evaluation of depressive symptoms in older caregivers. Arch Clin Psychiatr. 2015;42(2):45-51.

33. Inouye K, Pedrazzani ES, Pavarini SCI, Toyoda CY. Perceived quality of life of elderly patients with dementia and family caregivers: evaluation and correlation. Rev Latinoam Enferm. 2009;17(2):187-93.

34. Gratão ACM, Do Vale FAC, Roriz-Cruz M, Haas VJ, Lange C, Talmelli LFS, et al. The demands of family caregivers of elderly individuals with dementia. Rev Esc Enferm USP. 2010;44(4):873-80.

35. Pinto JLG, Garcia ACO, Bocchi SCM, Carvalhaes MABL. Características do apoio social oferecido a idosos de área rural assistida pelo PSF. Ciênc Saúde Coletiva. 2006;11(3):753-64. 